\title{
Pendant triazole ring assisted mesogen containing side chain liquid crystalline polymethacrylates: Synthesis and characterization
}

\author{
T PALANI, C SARAVANAN and P KANNAN* \\ Department of Chemistry, Anna University, Chennai 600 025, India \\ e-mail: pakannan@annauniv.edu
}

MS received 28 November 2009; revised 5 September 2010; accepted 14 December 2010

\begin{abstract}
Two series of click chemistry assisted alkoxymethyl-1H-[1,2,3]-triazol-1-yl containing sidechain liquid-crystalline polymethacrylates were synthesized by free radical polymerization technique. Mesogen was linked to backbone through various spacer units. Monomers and polymers were characterized by FT-IR, ${ }^{1} \mathrm{H}$ and ${ }^{13} \mathrm{C}$-NMR spectral techniques. Thermal stability of polymers was confirmed by thermogravimetric analysis. Mesomorphic property and phase transition temperature of polymers were analysed by differential scanning calorimetry and polarized optical microscopy. Phase transition temperature and mesomorphic property of polymers with respect to insertion of polar alkoxy group on terminal triazole ring and spacer length between backbone and mesogen were investigated. Polymers exhibited grainy like textures under polarized optical microscopy. Spacer length between mesogen and backbone alters phase transition temperature of the polymers.
\end{abstract}

Keywords. Click chemistry; triazole; mesogen; liquid crystal polymers; polymethacrylates.

\section{Introduction}

Side-chain liquid crystalline polymers (SC-LCPs) have considerable interest in advanced electro-optic technology due to mesogenic side chain and low glass transition temperature. ${ }^{1}$ Craig et al. devised an empirical rule in liquid crystalline property of various SCLCPs by keeping constant mesogenic group and spacer lengths and changing their backbone vice versa. ${ }^{2,3}$ Various synthetic methods of SC-LCPs have been reported in the literature with mesogenic groups such as 4-methoxybiphenyl, 4-cyanobiphenyl, and 4substituted phenyl benzoates. ${ }^{4,5}$ A number of nemetogens were copolymerized with various azobenzene containing side chain polymers for analysing their photo alignment with respect to switching property of azobenzene unit. ${ }^{6-9}$ During the past decades large number of liquid crystalline compounds containing heterocyclic units have been synthesized. ${ }^{10-12}$ Interest in such compounds arises from incorporation of heteroatoms can result in prominent changes in the corresponding liquid crystalline phases and/or physical

\footnotetext{
*For correspondence
}

property of the observed phases, because most of the usual heteroatoms ( $\mathrm{S}, \mathrm{O}$ and $\mathrm{N}$ ) introduced are chemically classified as more polarizable than carbon. ${ }^{13-15}$ However, it is important to extend molecular design of liquid crystals to involve other ring systems from not only theoretical, but also practical point of view. Particularly, liquid crystalline compounds containing five-membered heterocyclic rings have been successfully evaluated. ${ }^{16,17}$ It was found that non-linear heterocyclic liquid crystals, such as pyrazole, furan, thiophene, and isoxazole derivatives with terminally positioned heterocyclic ring form smectic or nematic phase at low temperature and in wide temperature range are well-studied. ${ }^{18,19}$ In addition, presence of heteroatom has contributed to increasing molecular dipole and dielectric anisotropy. ${ }^{20}$ Compounds containing five-membered ring such as [1,2,3]-triazole formed by [2+3] dipolar cycloaddition reaction between an organic azide and terminal alkyne, also known as 'Click Chemistry' has attracted much attention in the field of materials chemistry ${ }^{21}$ organic chemistry $^{22}$, supramolecular chemistry ${ }^{9}$ and drug discovery. ${ }^{23}$ Gallardo et al. ${ }^{12}$, have employed click chemistry to synthesize number of non-linear heterocyclic 
chiral liquid crystalline compounds with three and fourmembered ring systems containing [1,2,3]-triazole ring at a terminal position of rigid core and characterized their mesomorphic property. Compounds containing three-membered ring systems such as [1,2,3]-triazole ring at a terminal position was unable to exhibit liquid crystalline property. ${ }^{24}$ Nevertheless, introduction of polar alkoxy group through methylene carbon at the terminal $[1,2,3]$-triazole ring of same three-membered ring systems displayed liquid crystallinity. ${ }^{25}$ Thus, the present work deals with synthesis of two homologous series of non-linear heterocyclic liquid crystalline polymers namely, poly[4-(4-alkoxymethyl)-1H-1,2,3-triazole-1-yl-4methacryloyloxyalkyloxy benzoate]s using click chemistry with introduction of polar groups at terminal position in the heterocyclic ring through methylene group and investigated their mesomorphic property and their structure-property relationships.

\section{Experimental}

\subsection{Materials}

Methanol, ethanol, phenol, THF, diethyl ether, chloroform, triethylamine, dimethylformamide (DMF) (SRL, India) and other solvents were purified by reported procedures. ${ }^{26}$ Propargyl alcohol, $p$-aminophenol, 4hydroxybenzoic acid, dimethylsulfate and diethylsulfate and 2, 2'-azobisisobutyronitrile (AIBN) (Merck, Germany) were used as received. Silica gel (MN Kieselgel 100-200 mesh) was used for column chromatography. Methacrylic acid, hydroquinone, and 1, 6hexanediol, 1, 8-octanediol, 1, 10-decanediol, (Fluka, Switzerland) were used as supplied. 4-Azidophenol (1), 3-methoxy propa-1-yne (2), 3-Ethoxy prop-1-yne (3), 4[4-(methoxymethyl)-1H-[1,2,3]-triazol-1-yl]phenol (7), 4-[4-(ethoxymethyl)-1H-[1, 2, 3]-triazol-1-yl] phenol $(8)^{25}$, 6-Bromo-1-hexanol, 8-bromo-1-octanol, 10bromo-1-decanol, methacryloyl chloride ${ }^{27}$ were synthesized by reported procedures.

\subsection{Monomer ia-ic and iia-iic}

Monomers were prepared using similar procedure from the corresponding compounds. The typical procedure for the synthesis of ia is as follows: Compound 7 $(2.16 \mathrm{~g}, 0.01 \mathrm{~mol})$ in dichloromethane was added under nitrogen to a solution of compound $4(3.43 \mathrm{~g}$, $0.01 \mathrm{~mol})$, DMAP $(1.37 \mathrm{~g}, 0.01 \mathrm{~mol})$ and DCC $(2.31 \mathrm{~g}, 0.01 \mathrm{~mol})$ in $100 \mathrm{~mL}$ of absolute dichloromethane under stirring. Subsequently, the reaction mixture was stirred for $24 \mathrm{~h}$ at room temperature. Resultant solution was filtered, washed with water, brine and dried over anhydrous sodium sulphate. Crude product was purified by column chromatography (silica gel, hexanelethyl acetate) to give monomer ia as colourless solid (yield: 64\%): Since each series of monomers having same structural units with minor changes in spacer lengths, representative spectral data provided for each series of monomers as follows.

2.2a ia: FT-IR ( $\left.\mathrm{KBr}, \mathrm{cm}^{-1}\right)$ : 2952 and $2876\left(-\mathrm{CH}_{2}-\right)$, 2924 and $3039\left(-\mathrm{C}-\mathrm{CH}_{3}\right), 1615\left(-\mathrm{C}=\mathrm{CH}_{2}\right), 885(o-$ substituted aromatic), ${ }^{1} \mathrm{H}$ NMR (400 $\left.\mathrm{MHz}, \mathrm{CDCl}_{3}\right) \delta$ : $8 \cdot 15(d, 2 \mathrm{H}, \mathrm{Ar}), 7.98(s, 1 \mathrm{H}$, triazole-CH), $7.79(s, 2 \mathrm{H}$, Ar), $7.39(s, 2 \mathrm{H}, \mathrm{Ar}), 6.98(s, 2 \mathrm{H}, \mathrm{Ar}), 6.10(s, 1 \mathrm{H},-$ $\left.\mathrm{C}=\mathrm{CH}_{2}\right), 5.55\left(s, 2 \mathrm{H},-\mathrm{C}=\mathrm{CH}_{2}\right), 4.66(s, 2 \mathrm{H}$, triazole$\left.\mathrm{CH}_{2}-\mathrm{O}-\right)$, 4.09 ( $\left.s, 2 \mathrm{H}, \mathrm{Ar}-\mathrm{O}-\mathrm{CH}_{2}-\right), 3.85(s, 3 \mathrm{H},-$ $\left.\mathrm{CH}_{2}-\mathrm{O}-\mathrm{C}(=\mathrm{O})-\right), 3.37\left(\mathrm{~s}, 3 \mathrm{H},-\mathrm{OCH}_{3}\right), 1.95-1.25(\mathrm{~m}$, $\left.11 \mathrm{H},-\left(\mathrm{CH}_{2}\right)_{4}-,-\mathrm{CH}_{3}\right) .{ }^{13} \mathrm{CNMR}\left(400 \mathrm{MHz}, \mathrm{CDCl}_{3}\right) \delta$ : $183.6,179.5$ (carbonyl), 162.3, 161.7, 156.6, 142.2, $139 \cdot 5,134 \cdot 9,131 \cdot 4,130 \cdot 9,126 \cdot 2,125 \cdot 4,123 \cdot 6,122 \cdot 1$, $119 \cdot 4,117 \cdot 6,109 \cdot 8$ (aromatic), 71.3, 68.3, 65.8, 58.4 $\left(-\mathrm{O}-\mathrm{CH}_{3}\right.$, triazole- $\mathrm{CH}_{2}-\mathrm{O}, \mathrm{Ar}-\mathrm{O}-\mathrm{CH}_{2}-,-\mathrm{CH}_{2}-\mathrm{O}-\mathrm{C}$ $(=\mathrm{O})-), 32 \cdot 9,32 \cdot 3,29 \cdot 8,27 \cdot 2,24 \cdot 9,25 \cdot 8,24 \cdot 4,18 \cdot 8$, $11 \cdot 6$ (aliphatic).

2.2b iia: FT-IR ( $\left.\mathrm{KBr}, \mathrm{cm}^{-1}\right): 2958$ and $2872\left(-\mathrm{CH}_{2}-\right)$, 2931 and $3026\left(-\mathrm{C}-\mathrm{CH}_{3}\right), 1619\left(-\mathrm{C}=\mathrm{CH}_{2}\right), 891(o-$ substituted aromatic), ${ }^{1} \mathrm{H}$ NMR $\left(400 \mathrm{MHz}, \mathrm{CDCl}_{3}\right) \delta$ : $8.16(\mathrm{~d}, 2 \mathrm{H}, \mathrm{Ar}), 7.98(s, 1 \mathrm{H}$, triazole- $\mathrm{CH}), 7.77(s, 2 \mathrm{H}$, $\mathrm{Ar}), 7.39(s, 2 \mathrm{H}, \mathrm{Ar}), 6.99(s, 2 \mathrm{H}, \mathrm{Ar}), 6.10(s, 1 \mathrm{H},-$ $\left.\mathrm{C}=\mathrm{CH}_{2}\right), 5.55\left(s, 2 \mathrm{H},-\mathrm{C}=\mathrm{CH}_{2}\right), 4.65(s, 2 \mathrm{H}$, triazole$\left.\mathrm{CH}_{2}-\mathrm{O}^{-}\right), 4.08\left(s, 2 \mathrm{H}, \mathrm{Ar}-\mathrm{O}-\mathrm{CH}_{2}-\right), 3.85(s, 3 \mathrm{H},-$ $\left.\mathrm{CH}_{2}-\mathrm{O}-\mathrm{C}(=\mathrm{O})-\right), 3.34\left(q, 2 \mathrm{H},-\mathrm{OCH}_{2}-\right), 1 \cdot 15-2 \cdot 01$ $\left(\mathrm{m}, 18 \mathrm{H},-\left(\mathrm{CH}_{2}\right)_{4}-,-\mathrm{CH}_{3},-\mathrm{CH}_{3}\right) .{ }^{13} \mathrm{CNMR}$ $\left(400 \mathrm{MHz}, \mathrm{CDCl}_{3}\right) \delta: 183 \cdot 7,179 \cdot 5$ (carbonyl), 162.8, $161 \cdot 2,157 \cdot 2,143 \cdot 2,138 \cdot 9,133 \cdot 9,132 \cdot 4,130 \cdot 9,126 \cdot 7$, $125 \cdot 5,123 \cdot 6,124 \cdot 1,118 \cdot 6,117 \cdot 3,109 \cdot 1$ (aromatic), $71 \cdot 5,68 \cdot 6,65 \cdot 6,60 \cdot 4,58.5\left(\mathrm{Ar}-\mathrm{O}-\mathrm{CH}_{2},-\mathrm{O}-\right.$ $\mathrm{CH}_{2}-\mathrm{CH}_{3}$, triazole- $\mathrm{CH}_{2}-\mathrm{O}-, \mathrm{Ar}-\mathrm{O}-\mathrm{CH}_{2}-,-\mathrm{CH}_{2}-\mathrm{O}-$ $\mathrm{C}(=\mathrm{O})-), 32 \cdot 5,33 \cdot 3,30 \cdot 8,28 \cdot 2,26 \cdot 9,26 \cdot 8,25 \cdot 4,19 \cdot 8$, $13 \cdot 6$ (aliphatic).

\subsection{Polymer Ia-IIc}

Polymers were synthesized by free-radical solution addition polymerization technique from the corresponding monomers using AIBN as an initiator in $\mathrm{THF}$ at $60^{\circ} \mathrm{C}$ for $48 \mathrm{~h}$. Typical procedure for the synthesis of polymer Ia is as follows: Monomer ia 
(400 mg, $0.67 \mathrm{~mol}$ ) and AIBN (2wt.\%) were dissolved in dry THF and gentle steam of nitrogen purged into the solution. The solution was kept in an oil bath at $60^{\circ} \mathrm{C}$ for $48 \mathrm{~h}$. Then the solution was cooled and poured into excess of methanol to precipitate the product. Crude polymer thus obtained was reprecipitated twice using chloroform and methanol. Purified polymer was dried at $45^{\circ} \mathrm{C}$ under vacuum for $48 \mathrm{~h}$ to afford colourless solid. Representative spectral data provided for each series of polymers appended below:

2.3a Ia: FT-IR $\left(\mathrm{KBr}, \mathrm{cm}^{-1}\right)$ : 2946 and $2881\left(-\mathrm{CH}_{2}-\right)$, 2921 and $3000\left(-\mathrm{CH}_{3}\right), 1601$ (aromatic $\left.-\mathrm{C}=\mathrm{C}-\right), 888(o-$ substituted aromatic), ${ }^{1} \mathrm{H}$ NMR $\left(400 \mathrm{MHz}, \mathrm{CDCl}_{3}\right) \delta$ : 8.25 (s, $1 \mathrm{H}$, triazole), $8.13(s, 2 \mathrm{H}, \mathrm{Ar}), 7 \cdot 85(s, 2 \mathrm{H}, \mathrm{Ar})$, $7.40(s, 2 \mathrm{H}, \mathrm{Ar}), 7.00(s, 2 \mathrm{H}, \mathrm{Ar}), 4.66(s, 2 \mathrm{H}$, triazole$\left.\mathrm{CH}_{2}-\right), 4.09\left(\mathrm{Ar}-\mathrm{O}-\mathrm{CH}_{2}-\right), 3.38\left(\mathrm{~s}, 5 \mathrm{H},-\mathrm{OCH}_{3},-\mathrm{CH}_{2}-\right.$ $\left.\mathrm{O}-\mathrm{C}(=\mathrm{O})^{-}\right)$1.86-1.09 (m, 13H, $-\mathrm{CH}_{3},-\left(\mathrm{CH}_{2}\right)_{4}{ }^{-},-$ $\left.\mathrm{CH}_{2}-\right) .{ }^{13} \mathrm{C}$ NMR $\left(400 \mathrm{MHz}, \mathrm{CDCl}_{3}\right) \delta: 183 \cdot 2,179.5$ (carbonyl), 161.7, 156.6, 142.2, 139.5, 132.2, 131.4, $126 \cdot 2,125 \cdot 4,122 \cdot 1,119 \cdot 4,109 \cdot 8$ (aromatic), 71.2, 68.3, $58.4\left(-\mathrm{O}-\mathrm{CH}_{2}\right.$, triazole- $\mathrm{CH}_{2}-\mathrm{O}, \mathrm{Ar}-\mathrm{O}-\mathrm{CH}_{2}-$, $\left.\mathrm{CH}_{2}-\mathrm{O}-\mathrm{C}(=\mathrm{O})-\right), 32 \cdot 9,32 \cdot 3,29 \cdot 8,24 \cdot 9,24 \cdot 4,18 \cdot 8$, $11 \cdot 6$ (aliphatic).

2.3b IIa: FT-IR ( $\left.\mathrm{KBr}, \mathrm{cm}^{-1}\right): 2948$ and $2871\left(-\mathrm{CH}_{2}-\right)$, 2919 and $3011\left(-\mathrm{CH}_{3}\right), 1598$ (aromatic $-\mathrm{C}=\mathrm{C}-$ ), 893 (o-substituted aromatic), ${ }^{1} \mathrm{H}$ NMR $\left(400 \mathrm{MHz}, \mathrm{CDCl}_{3}\right) \delta$ : $8.25(s, 1 \mathrm{H}$, triazole), $8.12(s, 2 \mathrm{H}, \mathrm{Ar}), 7.78(s, 2 \mathrm{H}, \mathrm{Ar})$, $7.46(s, 2 \mathrm{H}, \operatorname{Ar}), 7.01(s, 2 \mathrm{H}, \mathrm{Ar}), 4.69(s, 2 \mathrm{H}$, triazole- $\left.\mathrm{CH}_{2}-\right), 4 \cdot 11\left(\mathrm{Ar}-\mathrm{O}-\mathrm{CH}_{2}-\right), 3.40(s, 5 \mathrm{H},-$ $\left.\mathrm{OCH}_{3},-\mathrm{CH}_{2}-\mathrm{O}-\mathrm{C}(=\mathrm{O})-\right) 1.86-1.09\left(m, 13 \mathrm{H},-\mathrm{CH}_{3}\right.$, $\left.-\left(\mathrm{CH}_{2}\right)_{4}-,-\mathrm{CH}_{2}-,-\mathrm{CH}_{3}\right) .{ }^{13} \mathrm{CNMR}(400 \mathrm{MHz}$, $\left.\mathrm{CDCl}_{3}\right) \delta: 183 \cdot 4,179 \cdot 8$ (carbonyl), 161.9, 156.8, $142 \cdot 4,139 \cdot 8,132 \cdot 2,131 \cdot 5,126 \cdot 7,125 \cdot 4,122 \cdot 1$, $119.5,109 \cdot 4$ (aromatic), 71.2, 68.5, 58.6 $\left(-\mathrm{O}-\mathrm{CH}_{2}\right.$, triazole- $\left.\mathrm{CH}_{2}-\mathrm{O}-, \mathrm{Ar}-\mathrm{O}-\mathrm{CH}_{2}-,{ }^{-} \mathrm{CH}_{2}-\mathrm{O}-\mathrm{C}(=\mathrm{O})-\right)$, $32 \cdot 6,32 \cdot 4,29 \cdot 7,24 \cdot 6,24 \cdot 7,18 \cdot 6,14 \cdot 2,12 \cdot 8,11 \cdot 6$, (aliphatic).

\subsection{Measurements}

Chemical structure of intermediates and target materials were analysed by infrared spectra obtained from Bruker IFS 66V Fourier Transform spectrometer using $\mathrm{KBr}$ pellets and nuclear magnetic resonance spectroscopy using Joel EX-400 FT-NMR spectrometer in $\mathrm{CDCl}_{3}$ with TMS as an internal standard for both ${ }^{1} \mathrm{H}-\mathrm{NMR}$ and ${ }^{13} \mathrm{C}$-NMR spectra.
Weight-average molecular weight $(\overline{\mathrm{Mw}})$, numberaverage molecular weight $(\overline{\mathrm{Mn}})$ and polydispersity $(\overline{\mathrm{Mw}} / \overline{\mathrm{Mn}})$ of polymers were obtained on a PL-GPC model 210 chromatograph using DMF as eluent at $25^{\circ} \mathrm{C}$ and calibrated with polystyrene standard. Thermogravimetric analysis was performed on a Mettler TA3000 thermal analyzer in nitrogen atmosphere at a heating rate of $20^{\circ} \mathrm{C} \mathrm{min}{ }^{-1}$ with a sample weight of $3-5 \mathrm{mg}$. Transition temperatures and phase transition enthalpies were determined by differential scanning calorimetry (DSC) using a Perkin-Elmer DSC7 calorimeter at a heating rate of $5^{\circ} \mathrm{C}$ per min. The liquid crystalline textures were watched using a Euromex polarizing microscope equipped with a Linkem HFS91 heating stage and a TP93 temperature programmer. Samples were made by placing small quantity of materials between two thin glass cover slips, and the anisotropic behaviour observed by heating and/or cooling at the rates of $5^{\circ} \mathrm{C} / \mathrm{min}$. The photographs were taken with a Nikon FM10 camera and exposed on a Konica film.

\section{Results and discussion}

\subsection{Synthesis}

Two kinds of alkyloxy substituted click chemistry assisted mesogen containing side liquid crystalline polymethacrylates were synthesized by free radical addition polymerization technique in THF solution using AIBN as initiator at $60^{\circ} \mathrm{C}$ and influence of substituent on the terminal position and spacer length in the side chain on phase transition temperatures and mesomorphic property were investigated. All polymers were prepared by following synthetic routes as shown in scheme 1.

Introduction of different spacers between back bone and mesogenic unit enhanced the solubility of polymers in common organic solvents such as chloroform, dichloromethane, DMF and THF. Number average molecular weight and polydispersity index value of polymers were tabulated in table 1 and revealed that the polymers possess moderate molecular weights. Chemical structure of synthesized polymers was confirmed by FT-IR, ${ }^{1} \mathrm{H}$ and ${ }^{13} \mathrm{CNMR}$ spectral techniques. Figure 1 displays ${ }^{1} \mathrm{H}-\mathrm{NMR}$ spectrum of monomer iia in chloroform solution. The resonance signals for protons were assigned with alphabets are shown in the figure, all the protons in the monomers were accounted well with corresponding signals in the spectrum and are in accordance with targeted struc- 


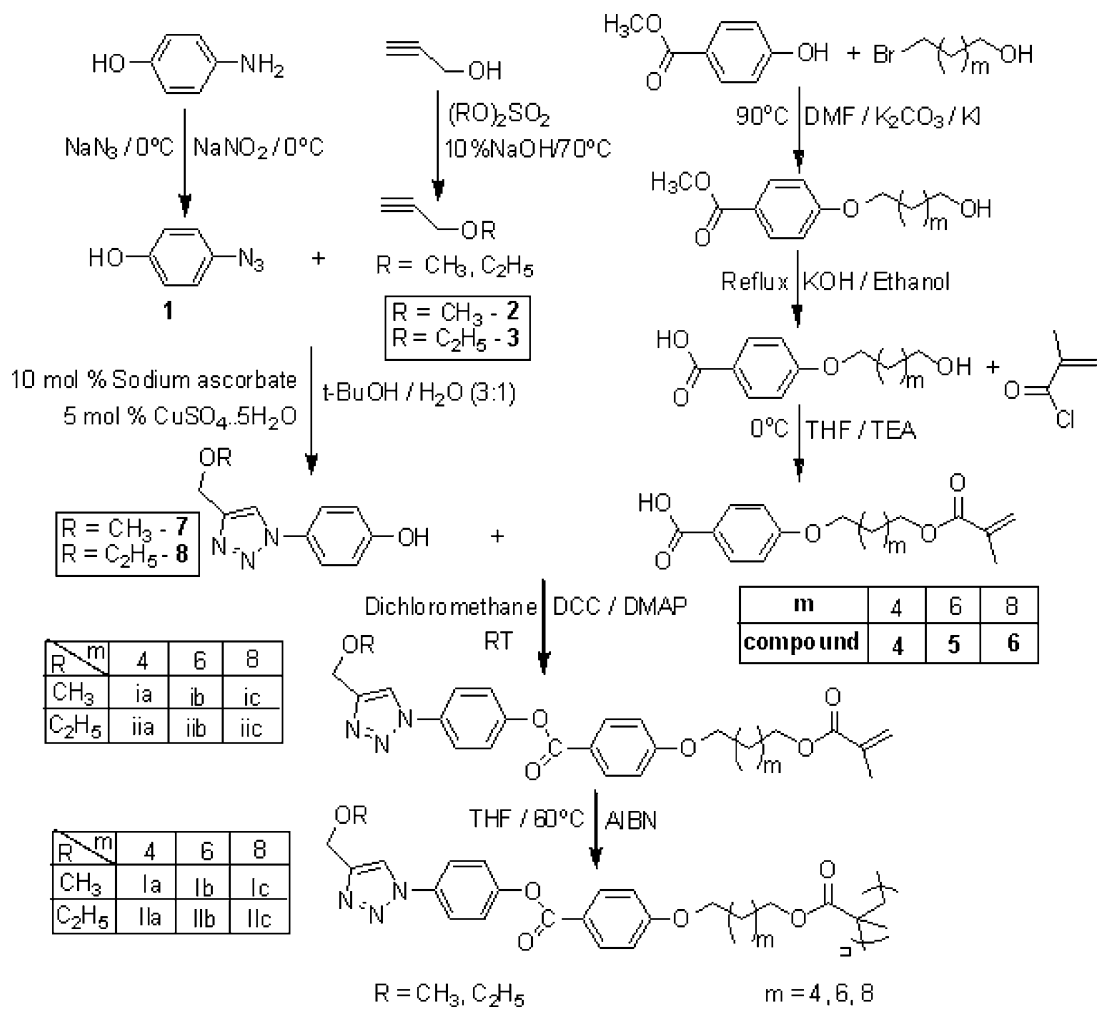

Scheme 1. Synthesis of polymer Ia-Ic and IIa-IIc.

tures. After polymerization, characteristic absorption band at $1634 \mathrm{~cm}^{-1}$ in FT-IR spectra corresponding to methacrylate double bond of monomer was completely disappeared. Similarly, chemical shift at $5.54 \mathrm{ppm}$ and $6 \cdot 10 \mathrm{ppm}$ assigned to vinyl proton of each monomer vanished after polymerization in their ${ }^{1} \mathrm{H}-\mathrm{NMR}$ spectra (representative ${ }^{1} \mathrm{H}-\mathrm{NMR}$ of polymers is given in figure 2). At the same time, an additional chemical shift of $-\mathrm{CH}_{2}-$ was observed at $0.98 \mathrm{ppm}$ in ${ }^{1} \mathrm{H}-\mathrm{NMR}$ spectra of all the polymers. The chemical shift at $125.3 \mathrm{ppm}$ in ${ }^{13} \mathrm{C}$-NMR spectrum corresponding to vinyl carbon is shifted to aliphatic region in the polymers. Methylene carbon adjacent to ether and ester linkage in the monomers resonated at $68.4 \mathrm{ppm}$ and $55.8 \mathrm{ppm}$ respectively and retained chemical shift values in the original position after polymerization. In addition, other chemical shifts representing the monomers were broadened in polymers confirmed the monomeric units completely involved in the polymerization reactions.

\subsection{Thermal property}

Thermal stability of polymers was examined using TGA with respect to substituent on the terminal position and spacer length between mesogen and the back bone. They displayed 5\% weight loss (Td) in nitrogen around $290-311^{\circ} \mathrm{C}$ and $50 \%$ weight loss

Table 1. TGA data polymers Ia-Ib and IIa-IIc.

\begin{tabular}{|c|c|c|c|c|c|c|c|}
\hline \multirow[t]{2}{*}{ Polymer } & \multirow[t]{2}{*}{$\overline{\mathrm{Mn}}$} & \multirow[t]{2}{*}{ PDI } & \multirow[t]{2}{*}{$\mathrm{n}$} & \multicolumn{2}{|c|}{$\begin{array}{l}\text { Weight loss } \\
\text { corresponding }\left({ }^{\circ} \mathrm{C}\right)\end{array}$} & \multirow[t]{2}{*}{$\begin{array}{l}\text { Total weight loss } \\
\text { at } 600^{\circ} \mathrm{C}\end{array}$} & \multirow[t]{2}{*}{$\begin{array}{l}\text { Char yield } \\
\text { at } 600^{\circ} \mathrm{C}\end{array}$} \\
\hline & & & & $5 \%$ & $50 \%$ & & \\
\hline Ia & 64,165 & $1 \cdot 11$ & 6 & 325 & 450 & 78 & 22 \\
\hline $\mathrm{Ib}$ & 58,856 & $1 \cdot 21$ & 8 & 320 & 428 & 80 & 20 \\
\hline Ic & 61,674 & 1.09 & 10 & 310 & 415 & 83 & 17 \\
\hline IIa & 62,856 & $1 \cdot 15$ & 6 & 318 & 440 & 79 & 21 \\
\hline $\mathrm{IIb}$ & 65,458 & $1 \cdot 16$ & 8 & 305 & 420 & 81 & 19 \\
\hline IIc & 63,124 & $1 \cdot 15$ & 10 & 290 & 405 & 82 & 18 \\
\hline
\end{tabular}




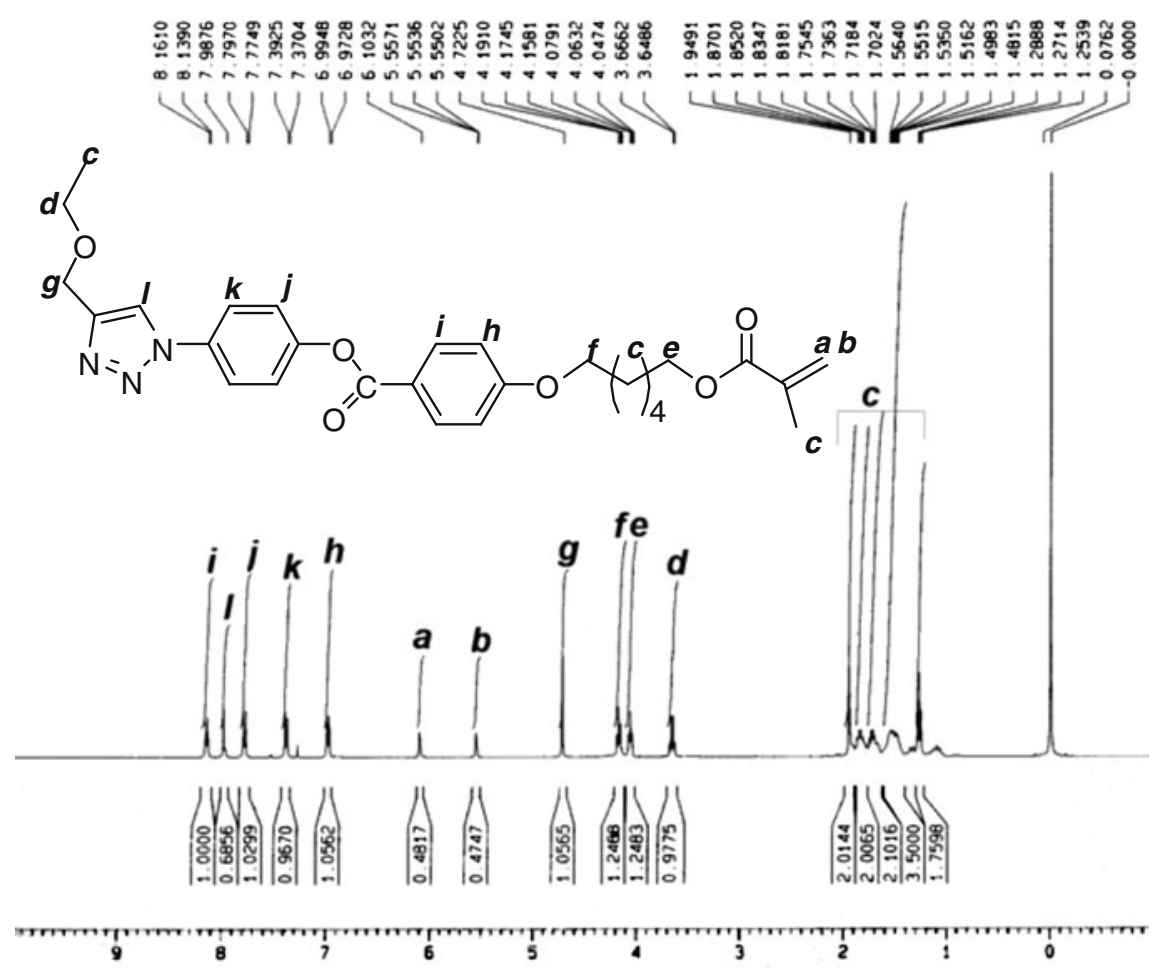

Figure 1. ${ }^{1} \mathrm{H}-\mathrm{NMR}$ spectrum of monomer iia in $\mathrm{CDCl}_{3}$.

observed beyond $405^{\circ} \mathrm{C}$ indicating their good thermal stability. The TGA traces of polymers Ia-Ic and IIa-IIc are shown in figures 3 and 4 respectively and their data are given in table 1 .
The polymers were decomposed through single stage decomposition phenomenon. On comparing our previous report, ${ }^{28}$ the triazole ring on the terminal position of polymethacrylate systems cleaves around
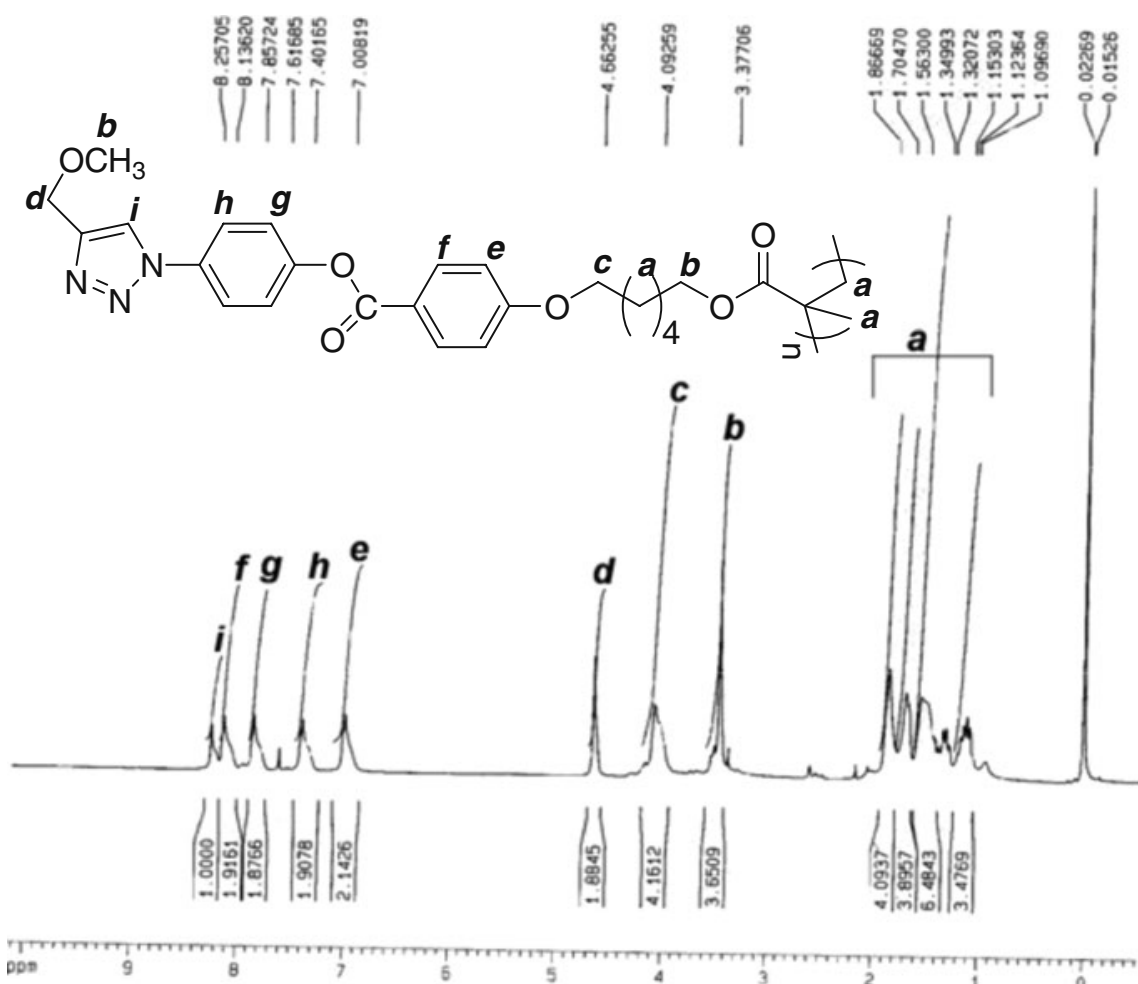

Figure 2. ${ }^{1} \mathrm{H}-\mathrm{NMR}$ spectrum of polymer Ia in $\mathrm{CDCl}_{3}$. 


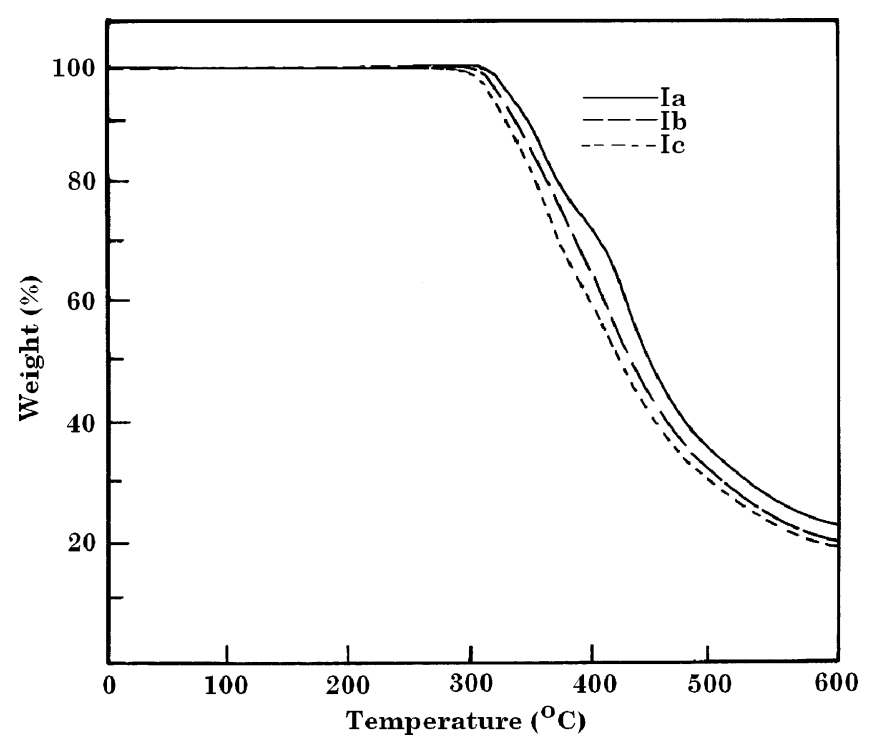

Figure 3. TGA thermograms of polymers Ia-Ic.

$306^{\circ} \mathrm{C}$, which is almost similar to the cleavage of ester linkages present in mesogen of the polymers, accordingly, these polymers demonstrated single stage decomposition. The methoxy substituted polymers (Ia-Ic) were stable in the range of $290-299^{\circ} \mathrm{C}$ and ethoxy substituted polymers (IIa-IIc) were stable in the range of $300-311^{\circ} \mathrm{C}$. The thermal stability data in table 1 revealed that thermal stability decreased with increasing methylene chain length from 6 to 10 attributed the presence of ether linkage and methylene chains in the spacer were expected to introduce greater flexibility and consequently brought down thermal stability. ${ }^{29}$ Among the methoxy and ethoxy substituents containing polymers, ethoxy-based polymers were less stable than that of methoxy-based polymers (table 1). This may be explained based on Baeyer's strain theory, heat of combustion per $-\mathrm{CH}_{2}-$ unit of methoxy are higher than that of ethoxy ${ }^{30}$ moiety. Decomposition of polymers was almost completed around $600^{\circ} \mathrm{C}$, after that no weight loss was observed. Char yield of

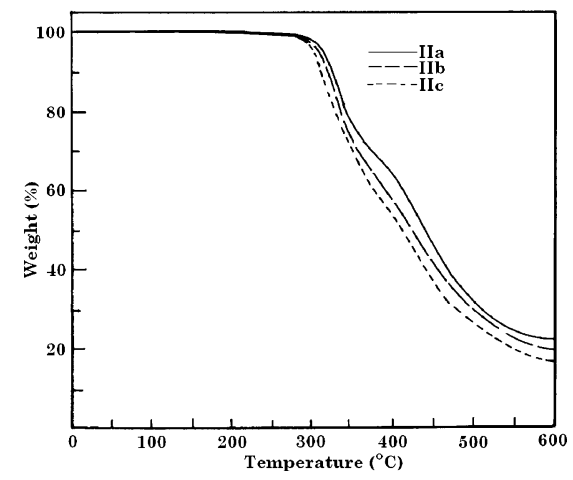

Figure 4. TGA thermograms of polymers IIa-IIc.

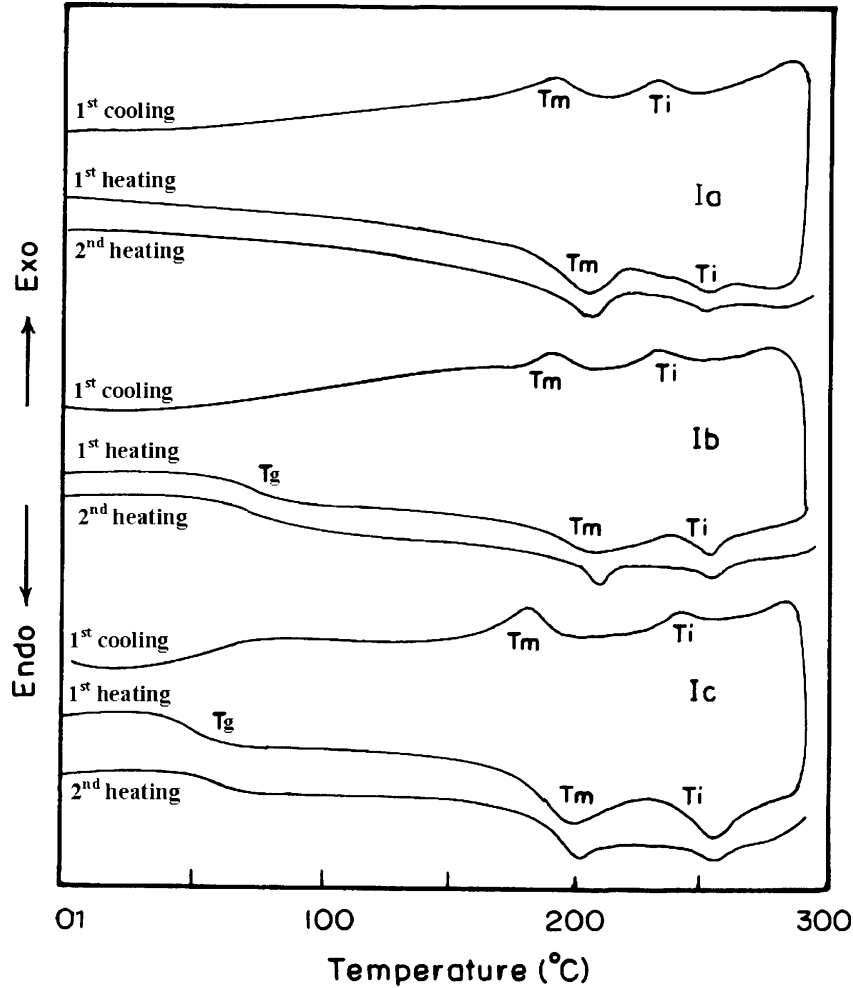

Figure 5. DSC thermograms of polymers Ia-Ic.

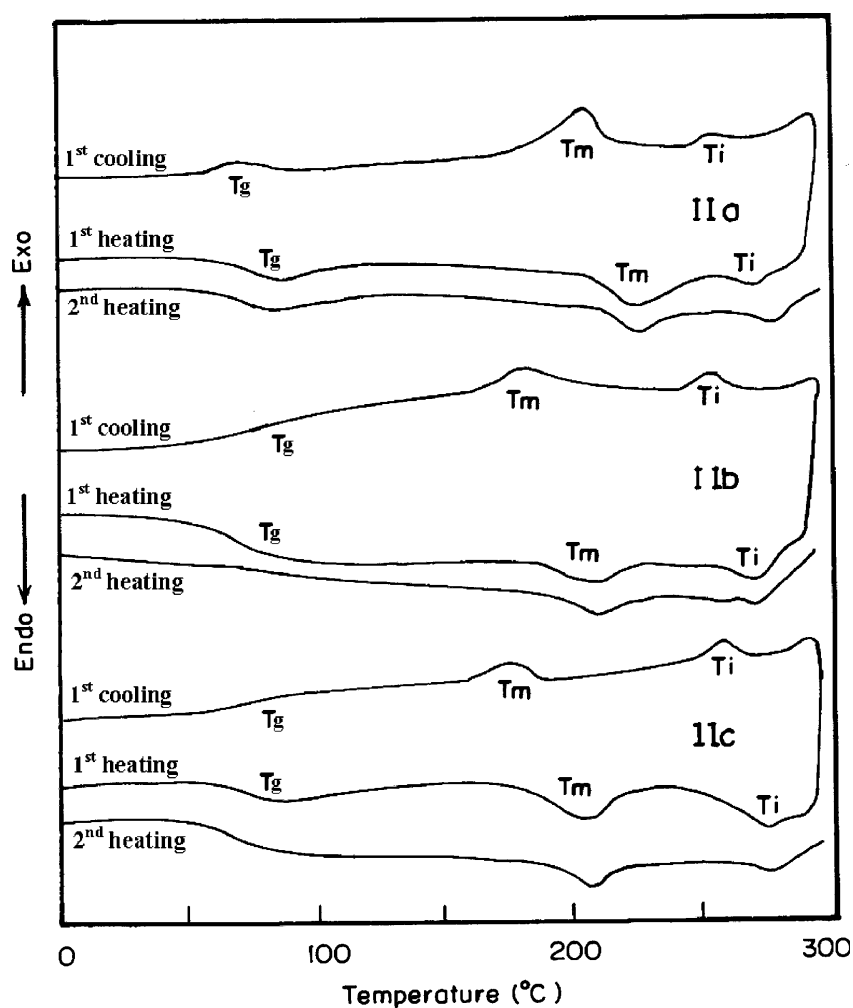

Figure 6. DSC thermograms of polymers IIa-IIc. 
Table 2. DSC and POM data of polymers Ia-Ib and IIa-IIc.

\begin{tabular}{|c|c|c|c|c|c|c|c|c|}
\hline \multirow[t]{2}{*}{ Polymers } & \multirow[t]{2}{*}{$n$} & \multirow[t]{2}{*}{$\operatorname{Tg}\left({ }^{\circ} \mathrm{C}\right)$} & \multicolumn{3}{|c|}{$\operatorname{DSC}\left({ }^{\circ} \mathrm{C}\right)$} & \multicolumn{3}{|c|}{ HOPM $\left({ }^{\circ} \mathrm{C}\right)$} \\
\hline & & & $\mathrm{Tm}$ & $\mathrm{Ti}$ & $\Delta \mathrm{T}$ & $\mathrm{Tm}$ & $\mathrm{Ti}$ & $\Delta \mathrm{T}$ \\
\hline Ia & 6 & - & 212 & 251 & 42 & 208 & 253 & 45 \\
\hline $\mathrm{Ib}$ & 8 & 75 & 210 & 262 & 49 & 212 & 264 & 52 \\
\hline Ic & 10 & 68 & 209 & 267 & 52 & 216 & 266 & 50 \\
\hline IIa & 6 & 85 & 220 & 271 & 51 & 218 & 271 & 53 \\
\hline $\mathrm{IIb}$ & 8 & 81 & 215 & 274 & 47 & 226 & 277 & 51 \\
\hline IIc & 10 & 78 & 215 & 277 & 47 & 230 & 279 & 49 \\
\hline ia & 6 & - & 121 & 147 & 26 & 124 & 146 & 22 \\
\hline $\mathrm{ib}$ & 8 & - & 118 & 151 & 33 & 119 & 149 & 30 \\
\hline ic & 10 & - & 110 & 148 & 38 & 115 & 153 & 38 \\
\hline iia & 6 & - & 113 & 138 & 25 & 114 & 141 & 27 \\
\hline iib & 8 & - & 108 & 145 & 37 & 108 & 147 & 39 \\
\hline iic & 10 & - & 95 & 138 & 43 & 97 & 136 & 39 \\
\hline
\end{tabular}

polymers was measured at $800^{\circ} \mathrm{C}$ to explore fire retardant property of these polymers. It revealed that char yield increased with decreasing spacer length (hexamethylene $>$ octamethylene $>$ decamethylene).

\subsection{Mesomorphic property}

The methoxy and ethoxy linked click chemistry assisted triazole ring containing mesogens displayed liquid crystalline phases. ${ }^{25}$ DSC experiments were conducted during second heating at $5^{\circ} \mathrm{C} / \mathrm{min}$ scanning rate and thermograms of Ia-Ic and IIa-IIc series of polymers are traced in figures 5 and 6 respectively. They exhibited two endothermic transitions between 96 and $233^{\circ} \mathrm{C}$. The low temperature one is due to crystalline-liquid crystalline $(\mathrm{Tm})$ and high temperature one is liquid crystallineisotropic (Ti) transitions. Phase transition temperatures of polymers are tabulated in table 2.
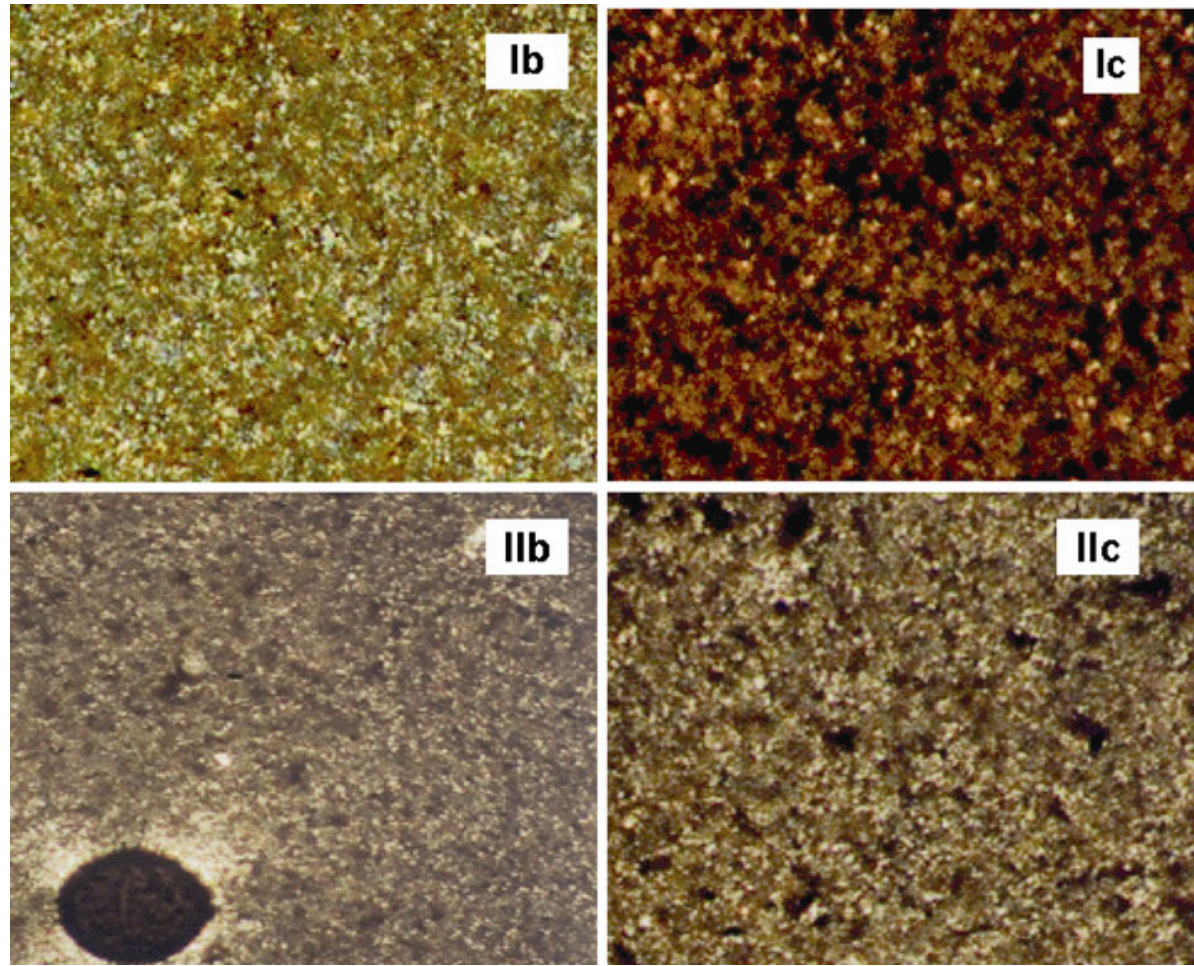

Figure 7. POM photographs of polymers Ib, Ic, IIb and IIc. 


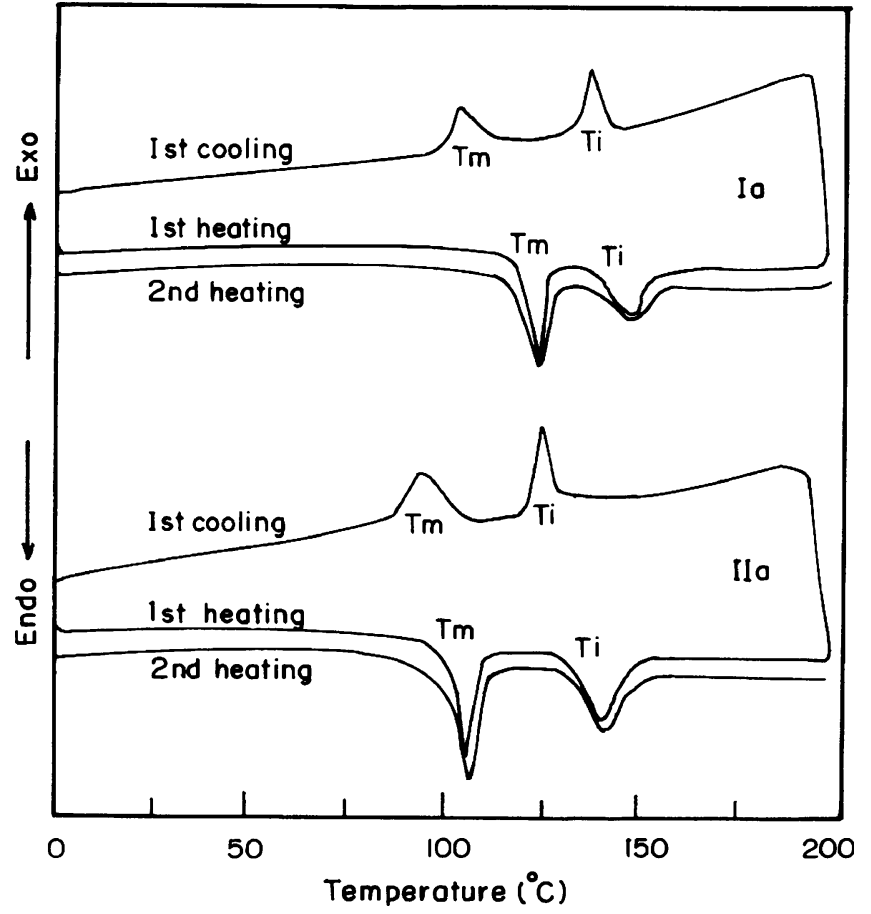

Figure 8. DSC thermograms of monomers ia and iia.

In addition to these two endothermic transitions, except Ia, remaining polymers exhibited one small hump just below the low temperature endothermic transition corresponding to glass transition (Tg) phenomena. The $\mathrm{Tg}$ value indicated in table 2 revealed that $\mathrm{Tg}$ decreases with increasing spacer length attributed to increase in spacer length could enhance segmental mobility to decrease $\mathrm{Tg}$. A broad first order peak is observed for melting transition and indicated a large amount of energy is involved, where as isotropic transition consumes relatively less amount of energy confirmed liquid crystalline phase formation of polymers. The Tm of polymers was in between 209 and $215^{\circ} \mathrm{C}$ and isotropic transition (Ti) is in between 251 and $277^{\circ} \mathrm{C}$. Liquid crystalline phase was observed in between the $\mathrm{Tm}$ and $\mathrm{Ti}(\Delta \mathrm{T}=\mathrm{Ti}-\mathrm{Tm})$. The $\Delta \mathrm{T}$ values revealed the broad mesophase for the polymers. DSC analysis disclosed $\mathrm{Tm}$ of polymers were decreased with increasing spacer length from 6 to 10 .

The polymers samples were analysed from their isotropic liquid in the POM for their mesomorphic property. On cooling from the isotropic liquid, they exhibited a uniform grainy like texture. Representative POM photographs Ib, Ic, IIa and IIc are shown in figure 7 and the phase transition temperatures observed in POM are summarized in table 2.

The phase transition temperatures noticed from the POM is in agreement with DSC data. Albeit, this mesogen containing low molecular weight liquid crystalline compounds displayed smectic-A phases, which was unable to show the same in polymers ascribed to the mesogen in the side-chain polymeric system is more favourable for nematic character than the smectic nature. The representative DSC thermograms and POM images for monomers ia-ic and iiaiic are given in figures 8 and 9, respectively and the transition temperatures are given in table 2. The polar-polar interaction between triazole rings in low molecular weight compounds is restricted in polymeric system leads to nematic like character than smectic textures which has advantages for commercial applications.

\section{Conclusion}

The click chemistry assisted triazole ring on the terminal position containing mesogens exhibited liquid crystalline phases. To investigate the same mesogen in the side chain polymethacrylate systems, we synthesized two series of side chain liquid crystalline polymers by free radical polymerization technique. The mesogen was linked to backbone through the various spacer units. All the
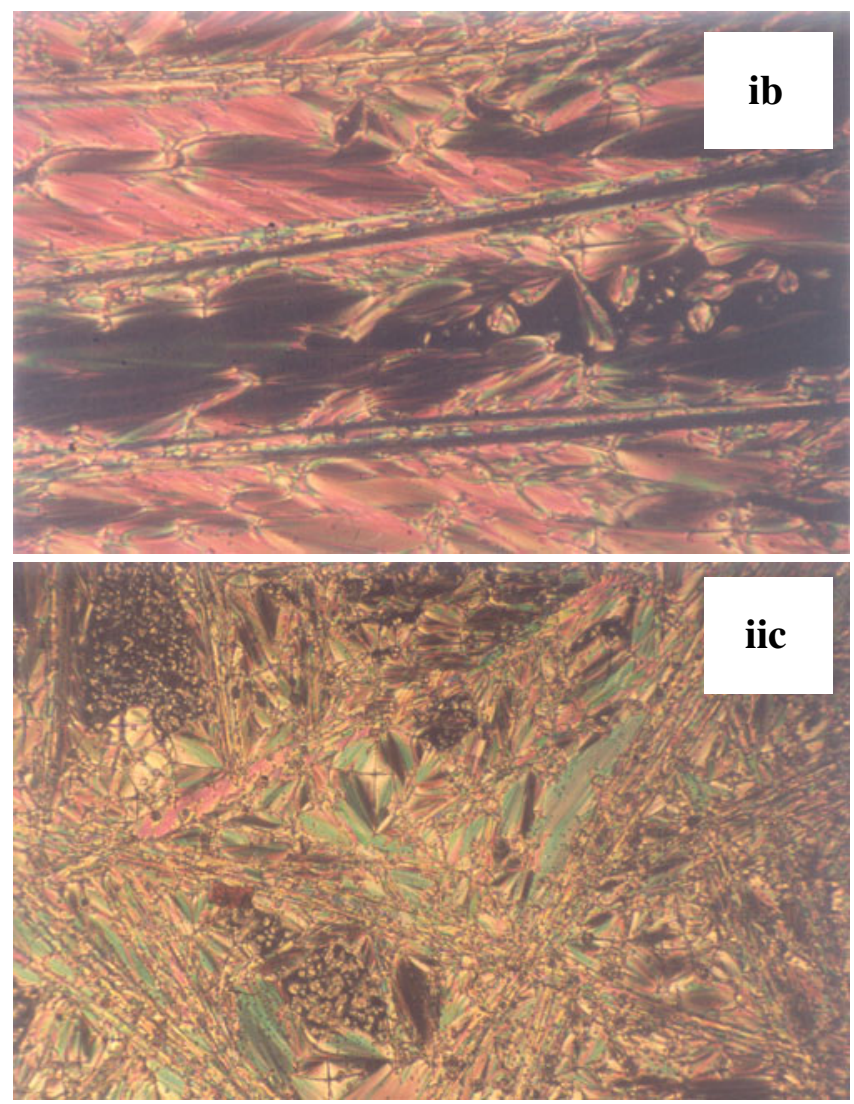

Figure 9. POM photographs of monomer ib and iic. 
monomers and polymers were characterized by FT-IR, ${ }^{1} \mathrm{H}$ and ${ }^{13} \mathrm{C}$-NMR spectral techniques. Thermal stability of polymers was confirmed by thermogravimetric analysis and revealed that thermal stability decreased with increasing methylene chain length from 6 to10. Between the two series of polymers, ethoxy-based polymers were less stable than that of methoxy-based polymers. The mesomorphic property and phase transition temperature of polymers were investigated by differential scanning colorimetric and polarized optical microscopy wherein, DSC analysis revealed that Tm of polymers were decreased with increasing spacer length from 6 to 10 . At the same time, $\mathrm{Tg}$ also decreases with increasing spacer length due to enhancement in segmental mobility of spacer units. All the polymers exhibited grainy textures attributed to polar-polar interaction between triazole rings in the low molecular weight compounds is highly restricted than that of polymeric system which leads to formation of nematic textures.

\section{Acknowledgement}

This research work was financially supported by University Grants Commission (UGC), New Delhi, Government of India [F. 31-110/2005 (SR)] and gratefully acknowledged.

\section{References}

1. Blackwood K M 1996 Science 273909

2. Craig A A and Imrie C T 1995 Macromolecules 28 3617

3. Craig A A and Imrie C T 1994 J. Mater. Chem. 4 1705

4. Coles H and Bankcraft 1993 Mol. Cryst. Liq. Cryst. 23797

5. Paskhovsky E, Litvina T G, Kostromin S G and Shibaev V P 1992 J. Phys. II (France) 21577

6. Bang C-U, Shishido A and T Ikeda 2007 Macormol. Rapid Commun. 281040

7. Han M and Ichimura K 2001 Macromolecules 3490
8. Bai S and Zhao Y 2001 Macromolecules 349032

9. Uchida E and Kawatsuki N 2006 Polymer 472322

10. Gallardo H and Favarin I 1993 Liq. Cryst. 13115

11. Paul H J K and Timothy M S 2007 J. Am. Chem. Soc. 12914042

12. Gallardo H and Maurmann L 2002 Mol. Cryst. Liq. Cryst. 37823

13. Vasconcelos U V, Dalmolin E and Merlo A A 2005 Org. Lett. 71027

14. Cristiano R, Ely F and Gallardo H 2005 Liq. Cryst. 32 15

15. Paraskos A J and Swager T M 2002 Chem. Mater. 14 4543

16. Silva L D, Gallardo H, Magnago R F and Begnini I M 2005 Mol. Cryst. Liq. Cryst. 4321

17. Bezborodov V, Kauhanka N and Lapanik V 2002 Mol. Cryst. Liq. Cryst. 411 103/[1145]

18. Tasaka T, Okamoto H, Morita Y, Abe K, Kasatani K and Takenaka S 2003 Bull. Chem. Soc. Jap. 76569

19. Keiki K, Michele CH and Timothy M S 1999 Chem. Matt. 11867

20. Kutsumizu S, Ishikawa T, Nojima S and Yano S 1999 Chem. Commun. 181

21. Ranjan R and Brittain W J 2007 Macromolecules 40 6217

22. Appukkuttan P, Dehaen W, Fokin V V and Eycken E V D. 2004 Org. Lett. 64223

23. Manetsch R, Krasinski A, Radic Z, Raushel J, Taylor P, Sharpless K B and Kolb H C 2004 J. Am. Chem. Soc. 12612809

24. Gilmar C, Fernando E and Hugo G 2005 Liq. Cryst. 32 1213

25. Srividhya D, Manjunathan S, Thirumaran S, Saravanan C and Senthil S 2009 J. Mol. Struct. 9277

26. Perrin D D and Armarigo W L F 1998 Purification of laboratory chemicals. New York: Pergamon Press

27. Mohan kumar, R, Saravanan C, Senthil S and Kannan P 2007 Euro. Polym. J. 432648

28. Saravanan C, Senthil S and Kannan P 2008 J. Polym. Sci. Part A: Polym. Chem. 467843

29. Fang-Jung H and Tzong-Lui 2004 J. Polym. Sci. Part A: Polym. Chem. 42290

30. Kannan P and Murugavel S C 1999 J. Polym. Sci. Part A: Polym. Chem. 373285 